\title{
Puasa Untuk Bumi
}

Gede H. Cahyana

Lektor Kepala Teknik Lingkungan Universitas Kebangsaan

Koran Pikiran Rakyat, 22 April 2021

Tema peringatan Hari Bumi (Earth Day) tahun 2021 ini adalah Restore the Earth. Pulihkan Bumi. Satu-satunya planet di tatasurya yang bisa didiami oleh manusia ini sedang sakit. Satu di antara beberapa cara untuk memulihkannya adalah puasa. Puasa dari aktivitas yang mencemari Bumi. Siapa yang harus puasa? Setiap orang sebagai individu dan orang sebagai pengelola masyarakat, yaitu pemerintah (pusat dan daerah). Ada tiga matra yang harus direstorasi dengan cara puasa, yaitu tanah, air dan udara.

Untuk tanah, setiap orang hendaklah puasa dari buang sampah botol plastik atau mengurangi (reduce) botol sejenis. Berikan botol kepada pemulung agar digunakan untuk keperluan lain (reuse, recycle). Bagaimana dengan sumber sampah botol plastik, yaitu pabrik makanan dan minuman, apakah harus ditutup? Haruskah pabrik softdrink dan makanan kemasan dihentikan? Jutaan orang bekerja di sektor industri makanan-minuman kemasan ini, mulai dari industri petrokimia hingga varian industri di hilirnya. Solusinya adalah gunakan bahan kemasan plastik yang ramah tanah sehingga mudah dihancurkan oleh mikroba tanah.

Adapun sampah organik seperti sisa nasi, sayur, ikan, daging, buah-buahan sebaiknya tidak dibuang ke luar rumah tetapi ditanam di dalam lubang di halaman rumah. Seminimal mungkin ditaruh di bak sampah yang akan diangkut oleh petugas sampah untuk dibawa ke TPA sampah. Memang faktanya tidak bisa 100\% tetapi bisa diupayakan sesedikit-sedikitnya. Sekian waktu kemudian sampah organik yang ditanam ini akan berubah menjadi pupuk. Bisa digunakan untuk pupuk tanaman hias, cabe, tomat, dll. Sampah organik ini menjadi penyubur tanah dan ikut memulihkan fertilitas tanah (Bumi). Tanah adalah bioreaktor alamiah yang mampu mengubah zat organik jasad manusia, hewan dan tumbuhan menjadi banyak unsur hara di dalam pupuk (fertilizer).

Bagaimana dengan peran pemerintah? Pemerintah merilis peraturan yang berpihak kepada kelestarian fungsi lingkungan dan peraturan ini wajib dilaksanakan oleh investor yang mengeksploitasi tanah untuk tambang batubara, emas, perak, nikel, minyak, gas, dll. Peraturan tersebut hendaklah dilaksanakan secara konsekuen. Tidak perlu terlalu banyak peraturan, apalagi setiap tahun ada peraturan baru sehingga terjadi inflasi peraturan. Apabila peraturan yang ada dilaksanakan secara taat asas maka hasilnya tentu efektif. Lemahnya penegakan hukum lingkungan inilah yang menjadi masalah saat ini.

Sebagai contoh, setiap pohon di kota yang tumbuh di tanah milik negara haruslah dirawat dan dipantau berkala. Tidak perlu semua pohon dipantau. Yang wajib dipantau adalah pohon besar yang rapuh akarnya atau pangkal batangnya berlubang. Kalau bisa disembuhkan tentu lebih baik dipertahankan. Kalau tidak bisa maka segera diregenerasi dengan pohon sejenis kemudian pohon yang sakit ini ditebang sebelum tumbang. Upayakan juga pohon-pohon 
tersebut tidak silang sengkarut dengan kabel telepon apalagi kabel listrik. Cegahlah korban harta dan jiwa sebelum terjadi.

Untuk air, setiap orang puasa dari perilaku buang air besar sembarang (open defecation). BABS ialah buang tinja di kebun, ladang, hutan, semak, sungai, selokan, pantai. Setiap rumah harus memiliki septic tank. Tugas pemerintah adalah menambah septic tank komunal di permukiman padat terutama di daerah kumuh (slum area) dan di daerah lain yang membutuhkan. Adapun pemilik pabrik tidak hanya wajib memiliki IPAL tetapi yang jauh lebih penting adalah wajib mengoperasikan IPAL dengan benar. Sebab, IPAL bukanlah lampu Aladdin, perlu dioperasikan dan dirawat sesuai dengan SOP. Demikian juga pemilik kebun dan sawah harus mengurangi pestisida agar air tanah dan air sungai terbebas dari racun pestisida terutama air yang digunakan oleh PDAM untuk air minum.

Untuk udara, setiap orang sebisa-bisanya tidak membakar sampah. Gunakan sepeda untuk jarak dekat di dalam perumahan atau berjalan kali. Pemerintah bertugas menyediakan transportasi masal yang nyaman dan menggunakan bahan bakar ramah udara. Kendaraan listrik menjadi opsi penting meskipun belum tentu lebih ekonomis. Adapun pabrik semampumampunya mengurangi penggunaan batubara meskipun sudah dinyatakan bukan limbah B3 lagi oleh PP No. 22/2021 tentang Penyelenggaraan Perlindungan dan Pengelolaan Lingkungan Hidup yang diturunkan dari UU Cipta Kerja. Keputusan ini dinyatakan fatal dan menyisakan pro-kontra di ranah pegiat dan pengamat lingkungan.

Andaikata semua aktivitas tersebut tidak bisa dilaksanakan oleh masyarakat berarti masyarakat tidak berniat serius untuk memulihkan kondisi Bumi. Begitu juga pemerintah, apabila peraturan hanya sekadar dibuat apalagi berpotensi merusak tanah, air, udara maka berarti pemerintah tidak berniat serius untuk menyembuhkan Bumi. Keikutsertaan pemerintah dalam peringatan Hari Bumi hanyalah rutinitas proforma yang tidak berdampak penting bagi Bumi dan sekadar business as usual serta teposaliro belaka kepada negara lain.

Apabila demikian realitasnya maka keengganan masyarakat dan pemerintah berpuasa untuk memulihkan Bumi kalah jauh dengan masyarakat dan pemerintah Amerika Serikat 51 tahun yang lalu. Kalah oleh spirit seorang ibu rumah tangga, Rachel Carson, penulis buku The Silent Spring (Musim Bunga yang Sunyi). Spiritnya ini kemudian disebarkan oleh senator Wisconsin Gaylord Nelson dalam orasi ekopolitiknya di Seattle pada tahun 1969. Tahun berikutnya sekitar 20 juta orang mengikuti deklarasi Earth Day pada 22 April 1970.

Tampaklah, individu dan pemerintah bersama-sama peduli pada kerusakan lingkungan akibat pencemaran tanah, air dan udara. Respons positif pada saat itu langsung diberikan oleh Presiden Richard Nixon dengan mendirikan Environmental Protection Agency (EPA) pada 2 Desember 1970 dan sukses merilis the Clean Water Act, the Clean Air Act, the Endanger Species Act.

Padahal jauh sebelum tahun 1970 itu, yaitu tahun 1945, Indonesia sudah memiliki pasal sosioekologi: pasal 33 ayat 3 UUD 1945 yang eksplisit menyatakan bahwa Bumi (tanah), air 
dan kekayaan alam yang terkandung di dalamnya dikuasai oleh negara dan dipergunakan untuk sebesar-besar kemakmuran rakyat. Deklarasi di dalam konstitusi negara kita ini sudah ada jauh sebelum Amerika Serikat peduli pada kerusakan lingkungan.

Kenapa sekarang justru kita tertinggal dalam ranah kepedulian terhadap lingkungan dan lebih mementingkan investasi yang merusak ekologi? Mampukah kita memulihkan Bumi jika demikian? Selamat memperingati Hari Bumi di tengah pandemi Covid-19. Selamat berpuasa untuk Bumi. *

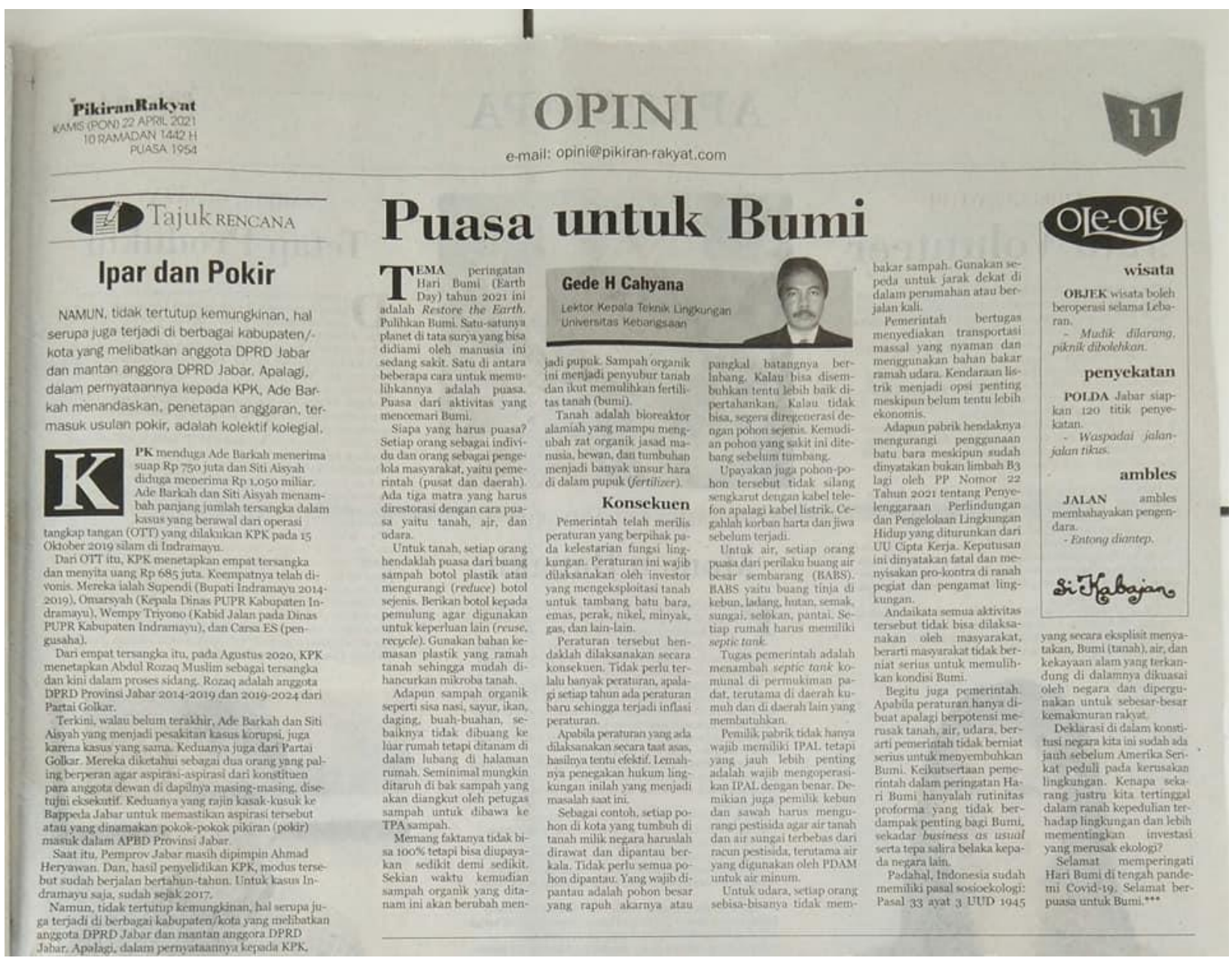

